\title{
Traduire
}

Une autre perspective sur r tr traduction

Revue française de la traduction

$239 \mid 2018$

Traduire l'art

\section{Les mots disparus de Pierre Larousse}

Marie-Céline Georg

\section{OpenEdition}

\section{Journals}

Édition électronique

URL : http://journals.openedition.org/traduire/1605

DOI : 10.4000/traduire.1605

ISSN : 2272-9992

\section{Éditeur}

Société française des traducteurs

\section{Édition imprimée}

Date de publication : 1 décembre 2018

Pagination : 95-96

ISSN : 0395-773X

\section{Référence électronique}

Marie-Céline Georg, "Les mots disparus de Pierre Larousse », Traduire [En ligne], 239 | 2018, mis en ligne

le 01 décembre 2018, consulté le 25 septembre 2020. URL : http://journals.openedition.org/traduire/

1605 ; DOI : https://doi.org/10.4000/traduire.1605 


\section{Compte rendu d'ouvrage \\ Les mots disparus de Pierre Larousse}

\section{Marie-Céline Georg}

Le père Noël connaît mes goûts, il sait que je collectionne les dictionnaires comme d'autres les timbres. L'année dernière, il a donc eu la riche idée de déposer sous le sapin Les mots disparus de Pierre Larousse. Grosso modo, un dictionnaire des mots qui ont été supprimés du Larousse.

II y a d'abord l'intérêt anecdotique de la lecture - oui, je lis le dictionnaire - pour se payer un petit plongeon nostalgique dans la langue du xixe siècle au gré de mots tombés en désuétude, métiers disparus (feu le meulier) ou variétés abandonnées (mais quel goût avait la cuissemadame ?). Je regrette néanmoins la brièveté de certaines définitions et surtout l'absence totale d'explications étymologiques. En voyant par comparaison la typographie microscopique du Petit Larousse illustré 2018 (plus de 2000 pages, " plus de 63200 mots [...], 28000 noms propres " en caractères de un millimètre de haut), je me dis que la présentation plus qu'aérée de ces Mots disparus (environ 200 pages en gros caractères illustrés par de magnifiques lettrines tirées du Grand Dictionnaire universel du xIxe siècle, l'œuvre maîtresse de Larousse) aurait supporté, sans devenir indigeste, quelques informations supplémentaires sur ces oubliés de la langue française.

Mais cet ouvrage a essentiellement le mérite de présenter la vie et le travail de Pierre Larousse, lexicologue, lexicographe, qui a révolutionné l'approche de l'enseignement du français et des outils utilisés à cet effet. Sa clairvoyance pédagogique mérite qu'on s'attarde sur la biographie d'un bourreau de travail au moins autant que sur le reste de l'ouvrage. Son ambition, "daguerréotyper la langue ", l'a conduit à recenser un grand nombre de mots qui révèlent non seulement sa vision de la langue à long terme, mais aussi la souplesse évolutive et la vivacité du français.

Avec mon œil de traductrice, j'ai apprécié ces mots en "-able "/ "-ible ", ces verbes en " dé- " (dépersuader, défâcher) qui mériteraient parfois d'être réhabilités pour éviter de fastidieuses circonvolutions sous prétexte que les correcteurs d'orthographe, les dictionnaires modernes et peut-être les rédacteurs que nous sommes, ne les connaissent plus. D'autres, il faut bien l'admettre, ne me manquaient pas - avais-je seulement eu vent de leur "disparition " ? comme certains interminables adverbes en "-ment". 
Loin d'être figée dans les couloirs de l'Académie, la langue est vivante. Ne l'oublions pas, nous qui passons nos journées à la manier, la bousculer, l'interroger, mais aussi à la forger. Cet ouvrage est peut-être vite parcouru, mais il me donne une furieuse envie de caser l'adverbe fiablement la prochaine fois que j'aurai besoin de décrire un instrument qui fonctionne de manière fiable. Parce que l'essentiel, c'est de pratiquer "l'art de bien rendre ses pensées ", comme disait Larousse.

mcgeorg.trad@aliceadsl.fr

Les mots disparus de Pierre Larousse - Avec une introduction de Bernard Cerquiglini et une présentation de Pierre Larousse par Jean Pruvost ; Larousse, Paris 2017.

ISBN 978-2-03-593837-4

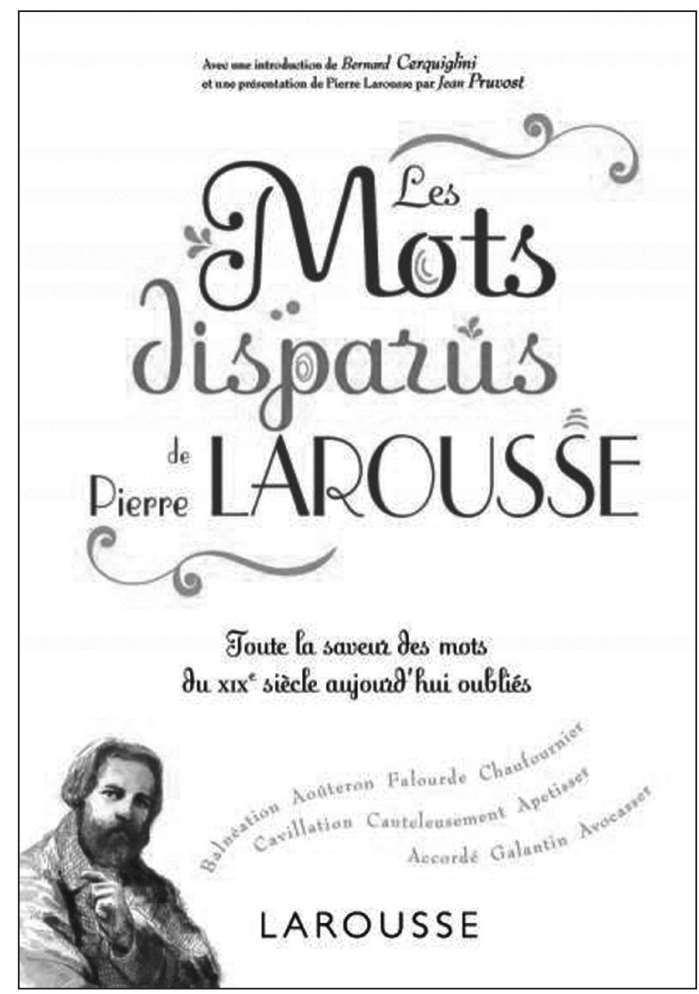

